\title{
A Fish Body Length Measuring Method Using an Underwater Video Camera in Combination with Laser Discharge Equipment
}

\author{
Kiyoshi Yoshihara \\ College of Bioresource Sciences, Nihon University, Kameino, Fujisawa, Kanagawa 256, Japan \\ (Received November 5, 1996)
}

The author has developed a device and a method to measure the body length of fish from played back images that reflect laser beams recorded on videotape by an underwater video camera with laser discharge equipment attached, and examined the usefulness of this measuring method through experimentation with dummies in a large water tank on land and in the field. The distances at which the laser spots could be recognized on various colors were, in ascending order, blue, as the lowest, followed by gray, yellow, white, red, and filefish skin; when a distance from the camera exceeds $2.5 \mathrm{~m}$, significant errors were observed.

In the field experimentation, the measurement was made using a device for the body length of kokanee salmons, Onchoryncus nerka, coming upstream in an artificial river, and it was compared with that of body length of salmons caught by a trap. Because the mode of both body length distribution coincided, it was confirmed that the usefulness of the measuring method of the body length by the underwater video camera with a laser beam discharge equipment attached. However, its use was limited to conditions of clear water and short distance to fish.

Key words: underwater video camera, laser beam, body length, kokanee salmon

The underwater video camera is widely used nowadays as a tool to observe the behavior of aquatic creatures. In the meantime, in the field of study of the operation of fishing gear or the catching of fish by fishing gear in the sea, or the observation of fish gathering at an artificial reef, its use as an important information source, has been developed in a variety of ways to suit the objectives of research, ${ }^{1,2)}$ and its application will be further diversified in the future.

Attempts have been made to make quantitative estimate of shoals of fish freely moving in the sea with an underwater video camera, and Hasegawa et $\boldsymbol{l}^{3}{ }^{3)}$ calculated the number of fish per capacity of field vision of the underwater video camera around underwater lamps from played backed images. Yasunaga et al ${ }^{4)}$ used an underwater video camera with a vision field fixing system at artificial reefs, and estimated the quantity of fish per $1000 \mathrm{~m}^{3}$ based on the number of fish gathered inside the cubic capacity of sight. On the other hand, Ellis ${ }^{5}$ compared the quantity estimated based on the catch by longline fishing and the quantity estimated from the vision of an underwater video camera in estimating the resources of juvenile pink snapper Pristipomoidos filamentosus and other fishes in the sea off Hawaii.

In these reports, the video camera was used in a clever manner, and if the image from the camera could provide information on the volume of resources and the number or size of fish directly, the underwater video camera would be used more widely and could become as a measuring instrument rather than an observation tool.

Development of the equipment, however, has not yet reached such a level, and it is still impossible to obtain quantitative data due to the limited distance of the reach of light in water.

The clarity of water, and the limited sight of a lens with present equipment as it exists.

Under the circumstances, the author developed a device for measuring the body length of fish. The device comprises an existing underwater video camera fixed with equipment capable of attaching two laser beams, and it measures the length of a fish body based on the distance between two bright spots formed on a monitor screen as the laser beams are reflected on the body of fish. The author also carried out studies to confirm the usefulness of the device by comparing experiment on dummies and actual measurements obtained in the field.

\section{Materials and Method}

\section{Principles of the Body Length Measurement}

The principles of the body length measuring method are shown in Fig. 1. Two semiconductor laser beams are discharged at a $5 \mathrm{~cm}$ width simultaneously from a laser beam discharge equipment attached to an underwater video camera. As the laser beam is a light with high directivity in a uniform medium, ${ }^{6}$ ) such as the air or the water, the two laser beams run in parallel, and if the two laser spots hit upon a target, the beams are marked as two bright red spots at the same width on a target. A videotape records the image of the target, and a measuring unit calculates its size from the played back images by means of the relative proportion of the width of the two laser spots and the length of the target. Figure 2 and Table 1 shows the specifications of the underwater video camera and the semiconductor laser. 

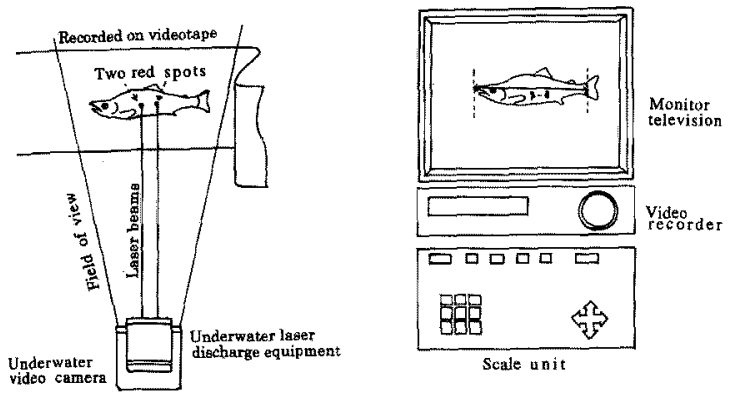

Fig. 1. Principle of measuring method.

Two laser beams are discharged from laser discharge equipment attached to underwater video camera.

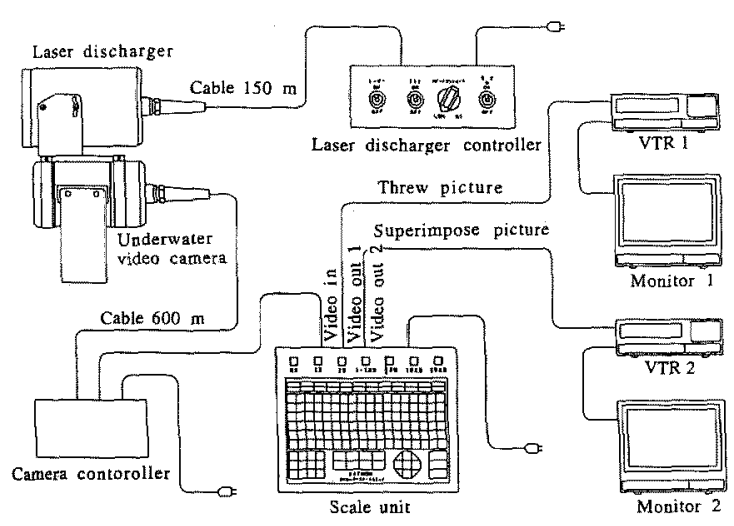

Fig. 2. System of underwater video camera and laser discharge equipment.

The semiconductor laser used here has a very small element, and hence it may play an important role in the measurement by virtue of its capacity to modulate the light directly by the change of electric current, its small electric consumption, and its low cost. ${ }^{6}$

\section{Dummy Experiment}

Before the field experiment, an experiment with dummies was carried out in an outdoor water tank of $6 \mathrm{~m}$ width $\times 1.1 \mathrm{~m}$ depth $\times 1 \mathrm{~m}$ height. Six dummies, of brass plates of $20 \mathrm{~cm} \times 7 \mathrm{~cm}$, painted blue, gray, yellow, white and red, respectively, and one covered with the skin of filefish, were used.

The experiment was carried out on a sunny summer day during noon and 2 P.M. when the sun light was strongest, and the dummies were moved $10 \mathrm{~cm}$ each for the total distance of $5 \mathrm{~m}$ from the underwater video camera and recorded.

Four experiment assistants measured the distances at which the laser spots could be recognized and the size of the dummies on the played back video images of the videotapes.

\section{Field Experiment}

The measurement of the body length of kokanee salmon (land locked sockeye salmon) Onchoryncus nerka, freely moving in water was carried out on an artificial river running in the site of the Nikko Branch of National Research Institute of Aquaculture, Fisheries Agency, as indicated in Fig. 3, and the result was compared with the distribution of body length of fish caught by a trap.

In this artificial river, about 1.5 millions juvenile kokanee salmon and others grown by artificial fertilization in this institute and the Lake Chuzenji Fisheries Cooperative Association, have been stocked every year. After a few years, many mature salmon and trout began migrating to this river to spawn, and they are caught by a trap.

An underwater video camera with laser discharge equipment attached was set at a place with $6 \mathrm{~m}$ width and $90 \mathrm{~cm}$ depth, to which a camera controller, a video deck, and a monitor television were connected with a $600 \mathrm{~m}$ cable, and a video recording was made.

In the meantime, in order to lower the luminous intensity in water, a shading net with a $70 \%$ shading effect of 2 $\mathrm{m}$ width was spread over the full $6 \mathrm{~m}$ width of the river. This net decreased the luminous intensity of the covered area down between 1,000 and 3,000 Ix at the surface of the water.

Though the image quality of the camera becomes poorer with the increase in length of the cable, there is no practical influence with a cable length of up to $1,000 \mathrm{~m}$, according to Miura. ${ }^{* 1}$ In fact, there was no special problem perceived in the process of measurement using the scale unit of the body length of fish on which the laser beams reflected based on the record images.

Table 1. Specifications of underwater video camera and laser discharge equipments

\begin{tabular}{|c|c|c|c|c|}
\hline \multicolumn{3}{|c|}{ Underwater video camera } & \multicolumn{2}{|c|}{ Underwater laser discharge equipments } \\
\hline \multirow[t]{6}{*}{ Camera } & \multicolumn{2}{|c|}{ Panasonic digital process color } & Laser & Semi-conductor laser \\
\hline & CCD camera & WL350 & Wavelength & $635 \mathrm{~nm}$ \\
\hline & Image sensor & $1 / 2$ inch & Collimator caliber & $4.8 \mathrm{~mm}$ \\
\hline & Resolution & 400 & Output & $3 \mathrm{mw}$ \\
\hline & Lense & f4.5 $1: 1.4$ & Interval of laser & $5 \mathrm{~cm}$ \\
\hline & & Auto Iris & Tilt angle & $60^{\circ} /$ second \\
\hline Housing material & & Stainless steel & Housing material & Stainless steel \\
\hline Submersible limit & & $50 \mathrm{~m}$ & Submersible limit & $30 \mathrm{~m}$ \\
\hline Camera controller & Panasonic & WV-PS $104 \mathrm{~A}$ & & \\
\hline Video timer & FOR.A & VTG-10 & & \\
\hline
\end{tabular}

\footnotetext{
${ }^{*}$ T. Miura: Abstracts for the meeting of the Japanese Society of Fisheries Science, April, 1989, p. 317.
} 


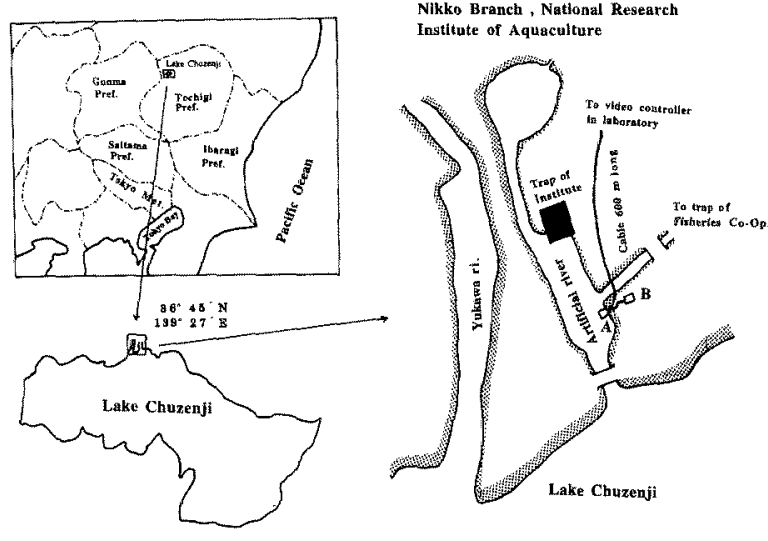

Fig. 3. Observation point at an artificial river.

A: Underwater video camera with laser discharge equipment. B: Laser controller.

The fish trapped by the institute are measured for the body length and the weight before the fish are artificially fertilized, and such body length is called "actual length".

The survey was carried out for 12 hours of continuous observation, from 5:30 A.M. to 5:30 P.M. every day for one month, from September 13 to October 13, 1994, covering the kokanee salmons coming upstream in the artificial river to spawn.

Measurement of the whole day on September 23, and a half day, till 3 P.M., on September 25, are missing due to failure of the laser discharge.

The condition of two laser spots on the body of fish were varied according to the postures of fish, which in turn caused errors in the measuremented results. To cope with this problem, swimming postures of fish were divided into four ranks before doing laser measurement, and the measurements of only one rank, which showed two laser spotsseen on the same side of the body (A ranked), are used here. Size of fish measured by use of laser beams was called the "laser length".

\section{Results}

Discriminated Distance of Laser Spots and Measuring Length of Dummies
On the dummy test, the length of the dummy on the videotape were measured five times by four experiment assistants, and the average and the standard deviation for distances at intervals of $1 \mathrm{~m}$ were calculated based on the obtained data, because there was no individual difference in the recognized distance, as shown in Table 2 . The luminous intensity at the surface of the water was $64,000 \mathrm{~lx}$, and that at $50 \mathrm{~cm}$ depth, where the dummies were located, was $16,700 \mathrm{~lx}$.

Visibility of the laser spots varied with the color of the dummies, such that all of the experiment assistants could not see them on the blue painted object beyond $1 \mathrm{~m}$ distance, and the visibility seemed to improve in the order of blue to gray, yellow, white, red, and the filefish skin.

Observing the measured figures, when a distance from the camera exceeds $2.5 \mathrm{~m}$, the measurement errors tended to increase.

\section{Comparison of the Body Length Distribution between the Laser Length and the Actual Length in the Field}

The counted number of kokanee salmon on the monitor screen was 5,790 in total, with 2,239 males, 1,304 females, and 2,247 sex unknown, and of these the number of fish that reflected the laser beams in A rank category was 1013 in total, with 598 males, and 415 females. On the other hand, the number of fish trapped by the Institute and measured for the body length was 512 in total, with 308 males and 204 females. Figure 4 shows the measurements by both ways by centimeter graduation of body length.

With respect to the actual length of male kokanee salmon, three large modes were observed, with the largest at the level of $25 \mathrm{~cm}$, followed by two others at the levels of $30 \mathrm{~cm}$ and $33 \mathrm{~cm}$, while there were two modes, at the levels of $26 \mathrm{~cm}$ and $31 \mathrm{~cm}$, for the measured length, indicating the latter was larger by $1 \mathrm{~cm}$. With respect to the sizes of female kokanee salmon, both the laser length and actual length showed a distribution of body length with two modes, comprising one group with the mode at the level of $25 \mathrm{~cm}$ or $26 \mathrm{~cm}$, and the other with the mode at the level of $30 \mathrm{~cm}$.

Examination of divergence of distribution by way of Chi-square test was $\chi^{2}=0.035$, d.f. $=9, P<0.01$ with males, and was $\chi^{2}=0.0062$, d.f. $=8, P<0.01$ with females, thus in either case no practical divergence between the laser length and the actual length was recognized, provid-

Table 2. Average values to measure by four persons at various dammies

\begin{tabular}{|c|c|c|c|c|c|c|c|c|c|c|c|c|}
\hline \multirow{2}{*}{$\begin{array}{c}\text { Distance } \\
\mathrm{cm}\end{array}$} & \multicolumn{2}{|c|}{ Blue } & \multicolumn{2}{|c|}{ Gray } & \multicolumn{2}{|c|}{ Bright yellow } & \multicolumn{2}{|c|}{ White } & \multicolumn{2}{|c|}{ Red } & \multicolumn{2}{|c|}{ Skin of filefish } \\
\hline & Avg. & Std. & Avg. & Std. & Avg. & Std. & Avg. & Std. & Avg. & Std. & Avg. & Std. \\
\hline 50 & 20.18 & 0.33 & 20.14 & 0.21 & 20.90 & 0.45 & 20.32 & 0.44 & 20.23 & 0.45 & 19.68 & 1.29 \\
\hline 100 & 20.20 & 0.73 & 19.92 & 0.62 & 20.09 & 0.48 & 19.89 & 0.32 & 20.32 & 0.34 & 20.15 & 0.48 \\
\hline 150 & & & 19.39 & 0.46 & 18.27 & 6.43 & 20.42 & 0.86 & 19.76 & 0.71 & 20.25 & 0.90 \\
\hline 200 & & & & & 21.81 & 1.47 & 20.63 & 1.56 & 20.06 & 0.99 & 20.24 & 1.26 \\
\hline 250 & & & & & & & 20.63 & 2.79 & 21.68 & 2.46 & 20.59 & 1.82 \\
\hline 300 & & & & & & & & & 22.02 & 3.05 & 21.96 & 2.42 \\
\hline 350 & & & & & & & & & & & 21.02 & 1.99 \\
\hline 400 & & & & & & & & & & & 21.76 & 3.06 \\
\hline 450 & & & & & & & & & & & & \\
\hline 500 & & & & & & & & & & & 19.03 & 1.37 \\
\hline Average & 20.19 & 0.31 & 19.98 & 2.99 & 20.08 & 1.58 & 20.37 & 0.68 & 20.45 & 0.70 & 20.44 & 0.74 \\
\hline
\end{tabular}




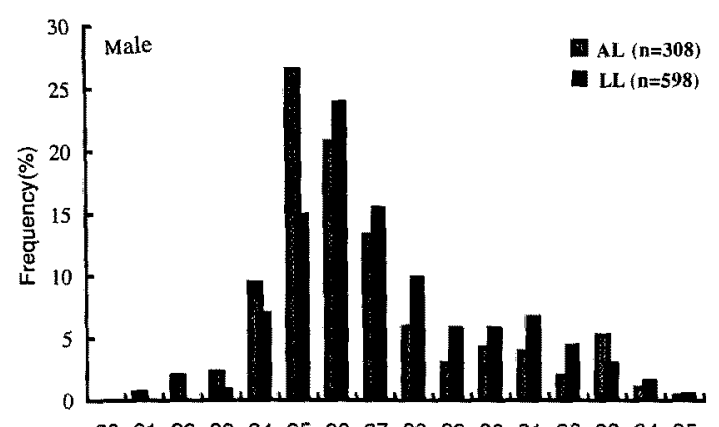

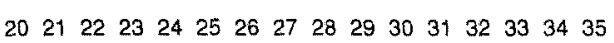
Body length in cm

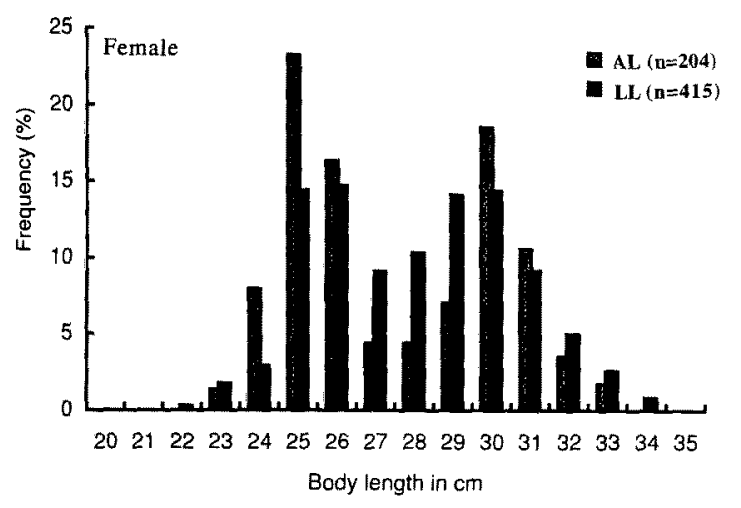

Fig. 4. Comparison of body length distributions of the actual length and laser length.

"AL" and "LL" mean actual length and laser length, respectively.

ing a result that the measurement of body length using the combination of an underwater video camera and a laser beam device was useful.

\section{Discussion}

The author has developed a method to measure the body size of fish freely moving in water by attaching laser discharge equipment onto an underwater video camera, which will become ever more popular for diversified applications in the future, and examined the usefulness of the device through the experimentation with dummies in a water tank on land, and through the experimentation in the field by comparison of the body length measured by the device and the actual length of kokanee salmons coming upstream to spawn.

In the dummy test, the errors tended to increase when the distance from the camera exceeded $2.5 \mathrm{~m}$. This seemed to be the result of that small erratic movement of a cursor, giving substantial influence on the measurement as the two points with a $5 \mathrm{~cm}$ width in between will look increasingly closer together on the target, to make the division less obvious with the increase in distance.

The semiconductor laser used in this experiment reaches more than $100 \mathrm{~m}$ in the air, but in the water, though it varied according to the color, no such reach can be expected, and errors will become larger for distances exceeding $3 \mathrm{~m}$.
Therefore some arrangement is necessary in order to use the same laser during a time of strong light. Nevertheless, obtained results suggested that the device could be quite usable if the circumstances such as luminous intensity in water were adjusted properly.

In the field experiment, no difference of body length distribution was recognized between the laser length and the actual length.

Sasakura ${ }^{7)}$ developed a special fish finder to measure the body length of fish freely moving in water, which is said to be useful for kinds of fish with comparatively simple distributions of body length. Unfortunately however, fish finders have the demerits of being incapable of distinguishing the kinds of fish.

As examples of length measurement using a laser beam, Chen et al. ${ }^{8}$ devised a method according to an automatic selection of seedling fry, and examined the measuring accuracy by using a laser wave for the body length measurement. However, because the equipments were developed for different purposes, this method cannot be applied to a fish freely swimming in the field. At almost the time, Miyahara $e t a l{ }^{9)}$ also developed their own ideas and devices separately to measure the body size using laser beams almost at the same time as the author did separately, and they suggested its usefulness, but they did not go so far as to develop a device that actually translates the data recorded on the videotape later, like the laser scalar used by the author.

Though the usefulness of this device has been confirmed, its application is limited to narrow areas due to shortcomings of the underwater video camera, such as limited fields of sight and the influence of water clarity, and the limited reach of laser beams in water due to absorption.

However, the problem of the narrow field of vision of a video camera may be solved to a certain extent by rotating the body of the camera.

In regard to the reach of laser beams, there is a chance that a greater reach may be available by the use of laser beams of other colors than the semiconductor laser, but the very expensive cost will make it impractical. Advancement in the technology of shorter wave semiconductor laser beams may offer a solution for this problem in the future, but as two laser spots will come closer with the distance, a minute erroneous movement of a cursor may exaggerate errors in the measurement, and thus its use may be inevitably limited.

Further, up to $5 \mathrm{~m}$ is the maximum as the best conceivable conditions for the kind of fish to be identified from the played back image of an underwater video camera, and hence its use is inevitably limited. Accordingly, it is thought that not much improvement can be expected even if the arrival distance of laser beams is stretched.

As a result, the method is considered to be useful at a place where fish must pass in larger concentration, like the site where our experiment was carried out and in circumstances of clear water with the possibility of freely adjusting sunlight.

Acknowledgments Deep appreciation is expressed here with to Dr. Mitsuo Sakai, Administrator of the Nikko Branch of National Research Institute of Aquaculture, Fisheries Agency, and other staff who offered 
the site and their cooperation in the fieid experiment.

\section{References}

1) The Fisheries Agency: An Intermediate Report, Suichuu tansa gijutsu kaihatsu kentou iinkai. 1986, pp. 25-86 (in Japanese).

2) M. Ariji and S. Suzuki: Questionnaire survey of remote operated vehicles and results of resistance test. Tech. rept. N.R.I.F.E. Fish. boat \& Instr., 10, 1-21 (1990) (in Japanese).

3) E. Hasegawa and $H$. Kobayashi: Observation on the fish behavior around the underwater lamp by fish sounder and underwater TV. $L a$ mer, 28, 131-138 (1990) (in Japanese).

4) Y. Yasunaga, T. Noma, J. Higano, S. Kubo, T. Takeuchi, A Setoguchi, A. Syoji, and M. Takeyama: A study on fluctuations in physico-chemical environment and shoaling behavior of fish at an average-sized artificial fish reef. Bull. N.R.I.F.E., 10, 1-58 (1989) (in
Japanese).

5) D. M. Ellis: Evaluation of video camera technique for indexing abundances of juvenile pink snapper Pristipomoides filamentosus, and other Hawaiian insular shelf fishes. Fishery Bulletin, 93, 67-77 (1995).

6) H. Saito: Characteristic and application of laser beam, in "Laser applicating technological handbook", Asakura shoten, Tokyo, 1991, pp. 227-229 (in Japanese).

7) T. Sasakura: Estimation of fish body length by fish finder, Gyosen, 313, 141-146 (1994) (in Japanese).

8) H. Chen and S. Yada: Studies on the accuracy of measuring fry body length by laser wave. Fisheries engineering, 31, 27-32 (1994).

9) N. Miyahara and H. Taguchi: Development of underwater measuring technology, Spc. Rep. Seikan interbrock and Seikan Technonet wark, 1, 1-5 (1992) (in Japanese). 